\title{
Three-Dimensional Digital-Mold Modeling and Sand-Printing for Replication of Bronze Mirror
}

\author{
Young Hoon $\mathrm{JO}^{1{ }^{1 *},}$, Jungmin Lee ${ }^{2}$ \\ ${ }^{1}$ Department of Cultural Heritage Conservation Sciences, Kongju National University, Gongju 32588, Korea \\ ${ }^{2}$ WIPCO Ltd., Yongin 16827, Korea
}

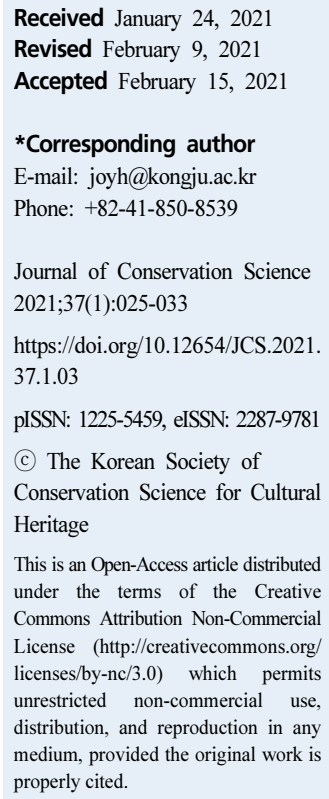

\begin{abstract}
To extend the application of digital technology to the replication of artifacts, meticulous details of the process and the diversity of three-dimensional (3D) printing output materials need to be supplemented. Thus, in this study, a bronze mirror with Hwangbichangcheon inscription was digitalized by 3D scanning, converted into a voxel model, and virtual conservation treatment was performed using a haptic device. Furthermore, the digital mold of the bronze mirror completed by Boolean modeling was printed using a 3D sand-printer. Such contactless replication based on digital technology reflects the stability, precision, expressivity, collectivity, durability, and economic feasibility of artifacts. Its application can be further extended to cultural products as well as such areas as education, exhibition, and research. It is expected to be in high demand for metal artifacts that require casting. If empirical studies through experimental research on casting are supplemented in the future, it could extend the application of digital technology-based contactless replication methods.
\end{abstract}

Key Words Digital technology-based contactless replication, Three-dimensional scanning, Three-dimensional sand-printing, Virtual conservation treatment, Digital mold, Bronze mirror

\section{INTRODUCTION}

Replication, a kind of recording, is one of the processes of conserving cultural heritage. It has been actively performed to conserve and manage cultural heritage, as well as the diversity of exhibition techniques. However, its methodology has constantly changed with the development of new materials and techniques employed by reproducers. In particular, recent advancement in high technology has led to several attempts in digital technology-based contactless replication to solve the issues of complex processes of the conventional contact method of replication and minimize secondary damage to artifacts (Di Franco et al., 2015; Merchán et al., 2019; Jo et al., 2020a).
Byun et al. (2009) and Ahn (2017) printed threedimensional (3D) scanning results of artifacts, colored them and treated their surface to complete the replication. Lee (2018) studied silicone mold-based casting techniques using the 3D printed output of the Great Gilt-bronze Incense Burner of Baekje. Lim and Choi (2020) reverse-engineered the damaged cannon used during the Joseon Dynasty using 3D scanning and printed it with a $3 \mathrm{D}$ printer to grasp the characteristics of the era regarding the shape and technology. Thus, 3D scanning and printing are employed as key technologies in contactless replication.

However, to extend the application of digital technology to artifact replication, there is a need for further studies to supplement the details of the process and the diversity of the 
3D printing output materials. In particular, it is essential to remove the surface corrosion and correct the shape deformation in order to reproduce the original appearance of the artifacts. This is the optimum method for ritual vessels used in ancestral rites and bronze mirrors that could be massproduced with molds (Yun and Cho, 2012; Yun et al., 2015).

In this study, a 3D scanning-based digital mold of a bronze mirror was modeled to advance the preceding methods of digital replication. Particularly, virtual conservation treatment was performed for the original modeling of the corroded bronze mirror, and the changes in shape were visualized numerically. In addition, to demonstrate the completed digital mold, a 3D sand-printer featuring high material similarity was employed for the printout. This study aims to propose a wide application of the digital mold in replicating artifacts along with the overall process of modeling and printing.

\section{STUDY TARGET AND METHODS}

\subsection{Study target}

Bronze mirrors were designed originally to reflect the face on the surface of well-polished copper plates. After losing their function as mirrors in the modern days, the metal crafts remain attractive owing to the various patterns used to decorate the back. Bronze mirrors are metal crafts, which have continuity from prehistoric times to the Joseon Dynasty, and are important artifacts that reflect religion and thoughts, not just simple household items. Mirrors were most popular in the Korean Peninsula during the Goryeo Dynasty, during which mirrors of various shapes and patterns were produced, and the number produced was the largest (Seol, 2015).

The study target was a bronze mirror with Hwangbichangcheon inscription, representing the Goryeo Dynasty, which is conserved by the National Science Museum. This mirror has been passed on from the Goryeo Dynasty in relatively large quantities among other bronze mirrors that have been identified so far (Kwon and Jo, 2019), and it is significant in that more mirrors were found in Goryeo than in China where they were first produced (Jung, 2015). Bronze mirrors with Hwangbichangcheon inscription are currently distributed in large quantities in various museums and institutions in Korea, and the elaborateness of the patterns and the state of conservation vary according to mirrors.

The bronze mirror studied herein was the eight-foliated mirror, and considering the overall conservation, it was in good condition. However, the mirror was covered by thin greenish rust with brown corrosion partly present. In particular, dark green corrosion on the inscription and rim was highly entrenched to the extent that it undermined aesthetic stability.

\subsection{Methods}

The digital-mold modeling and its printing for replicating the bronze mirror were performed in the order of $3 \mathrm{D}$ scanning, voxel modeling, virtual conservation treatment, Boolean modeling, and sand-printing (Figure 1). First, the 3D numerical data of the bronze mirror with Hwangbichangcheon inscription having overall thin and sophisticated patterns were obtained using a high precision scanner (HDI Advance R3X, LMI Technologies, Canada) with excellent accuracy and precision. The scanner operates with a triangulation method using white structured light and two stereo cameras, and it can obtain about 2.6 million points per scan ( 0.88 seconds) through binocular parallax

The on-site 3D scanning of the bronze mirror was performed 78 times with an accuracy of $65 \mu \mathrm{m}$, having the viewing angle of a pair of 12-mm lenses set to $400 \mathrm{~mm}$. The exposure value was maintained at $50.00 \mathrm{~ms}$ considering the surrounding conditions during the scan. FlexScan 3D software of LMI Technology was employed for the on-site 3D scanning and data processing, and Geomagic Design $\mathrm{X}$ software of 3D Systems was employed for editing and optimizing the 3D models.

For the virtual conservation treatment and digital-mold modeling of the completed 3D models, a voxel-based haptic

\begin{tabular}{|c|c|c|c|c|}
\hline 3D scanning & Voxel modeling & Virtual treatment & Boolean modeling & 3D sand printing \\
\hline Stereo vision (FOV: $400 \mathrm{~mm}$ ) & Voxelization & Haptic device & Boolean operation & $Z$ resolution : $0.26 \sim 0.38 \mathrm{~mm}$ \\
\hline Accuracy : $65 \mu \mathrm{m}$ & Resolution $0.3 \mathrm{~mm}$ & 3D sculpting software & Digital mold & Particle size : $140 \mu \mathrm{m}$ \\
\hline
\end{tabular}

Figure 1. Methods and processes of digital-mold modeling and 3D printing. 
device (Geomagic Touch X, 3D Systems, USA) and dedicated software (Geomagic Freeform Plus, 3D Systems, USA) were employed. The system applies force feedback to the user's hands to aid in vivid interactions with objects displayed in a virtual environment. The voxel-based clay modeling allows the flexible designing of 3D shapes (Jo et al., 2020a). The S-Max of ExOne printer was used for the $3 \mathrm{D}$ printing of a completed digital mold, and its layer thickness ranged from 0.26 to $0.38 \mathrm{~mm}$.

\section{RESULTS}

\subsection{D scanning and shape analysis}

The processing of numerical data acquired by $3 \mathrm{D}$ scanning has already been reported by a number of researchers (Kuş, 2009; Oh and Wi, 2018; Jo and Hong, 2019). In this study, it was basically completed with one 3D model after a series of processes, including registering, merging, and filtering of individual polygonal meshes. RGB textures were mapped to the final polygon mesh model after adjusting the brightness and chromaticity of the acquired colors during the scan, displaying the color of the bronze mirror surface and the location of the corrosion. The completed 3D model of the bronze mirror with the Hwangbichangcheon inscription was approximately 168,170 , and $5 \mathrm{~mm}$ in width, height, and thickness, respectively, and the inscription on the top was approximately $42 \mathrm{~mm}$ wide and $50 \mathrm{~mm}$ long, accounting for about a quarter of the total area (Figure 2).

The 3D numerical data consist of 1,093,209 point clouds and $2,186,418$ polygons in total, with a volume of 77,600 $\mathrm{mm}^{3}$. The distance between points shows a high resolution of $0.02 \mathrm{~mm}$, which clearly manifests not only the inscription (Figure 3a) and pattern (Figure 3b) on the bronze mirror but also the $3 \mathrm{D}$ shape and texture of the corrosion on the surface (Figure 3c). This implies that it can be used in a variety of

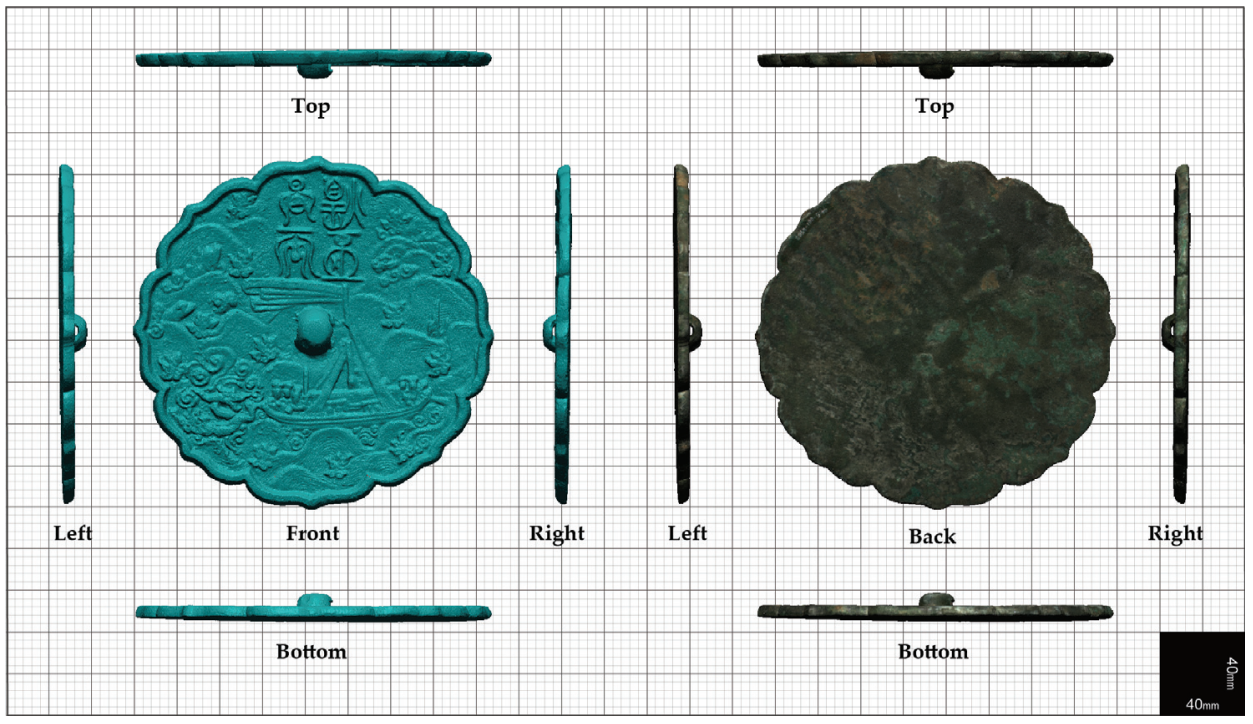

Figure 2. 3D scanning model of the bronze mirror with Hwangbichangcheon inscription.
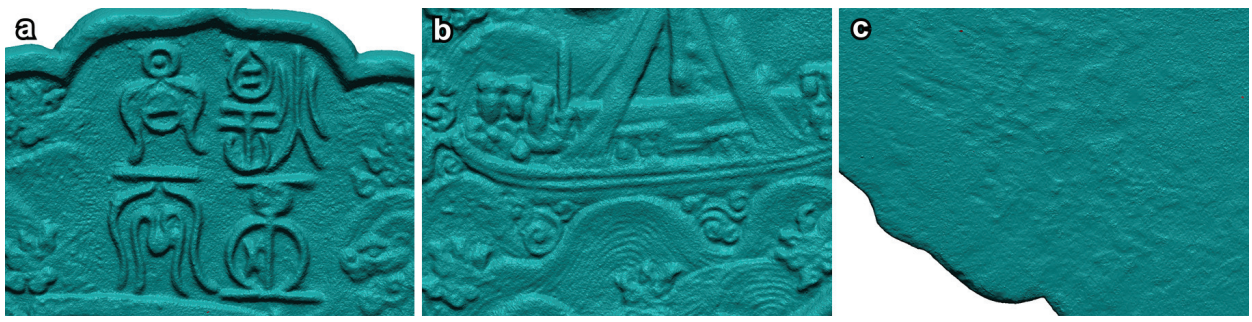

Figure 3. Detailed shape of the bronze mirror with Hwangbichangcheon inscription; (a) Inscription, (b) Patterns and designs, (c) Corrosion. 
ways, including restoration and replication, as well as the analysis of the state of the bronze mirror.

\subsection{Virtual conservation treatment}

The 3D model of the bronze mirror with the Hwangbichangcheon inscription has very precise highresolution numerical data, which is very important for recording. However, using it as the basic data for replication is difficult because even the corrosion entrenched on the surface of the mirror is scanned together. Therefore, replicating the original uncorroded bronze mirror requires the removal of any corrosion present on the surface in a virtual environment.

In general, 3D scanning is applied to opaque objects, and cultural heritages obtained through scanning are commonly expressed with the polygon mesh model of the surface. The polygonal mesh has great strengths in terms of data utilization and expandability. However, when the surface shapes are removed, the hollow interior is exposed, and this is a challenge. Therefore, for cultural heritages that require both external and internal information, a model having an inside volume is more appropriate than a polygon, and voxelization is essential for this purpose.

Thus, in this study, the 3D polygon mesh of the bronze mirror was converted to the voxel model with a resolution of $0.3 \mathrm{~mm}$, and then, virtual conservation treatment was performed using a haptic device to make the collisions and interference of data in a digital environment intuitively recognizable (Figure 4a). This provides a superior solution to creating unrestricted and complicated shapes than traditional modeling using a mouse. A system that combines the voxel modeling software with a haptic device has been widely employed by both domestic and foreign researchers (Abidi and Ahmad, 2015; Wu et al., 2016; Corrêa et al., 2019; Jo and Hong, 2019; Rastogi and Srivastava, 2019).

The corrosion present on the surface of the bronze model was removed manually by voxel-based physical collision (Figure $4 b$ ). The surrounding features were referenced over the virtual conservation treatment to ensure that the original form of the bronze model was not damaged, and the entire process was monitored by RMS deviation analysis. After removing the corrosion, the original volume $\left(77,660 \mathrm{~mm}^{3}\right)$ of the mirror decreased by about 233 to $77,367 \mathrm{~mm}^{3}$ (Figure
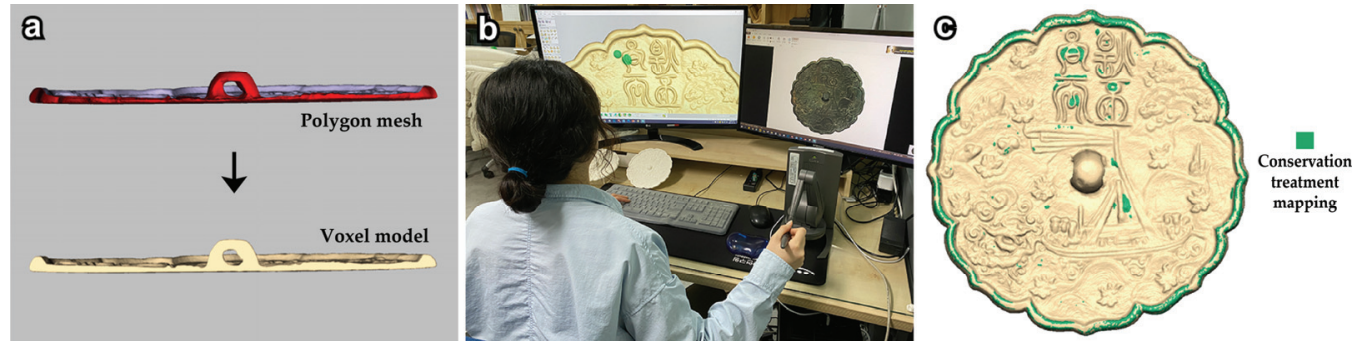

Figure 4. Virtual conservation treatment of the bronze mirror; (a) Voxelization of the polygon mesh model, (b) Virtual conservation treatment using the haptic modeling system, (c) Shape comparison after treatment.

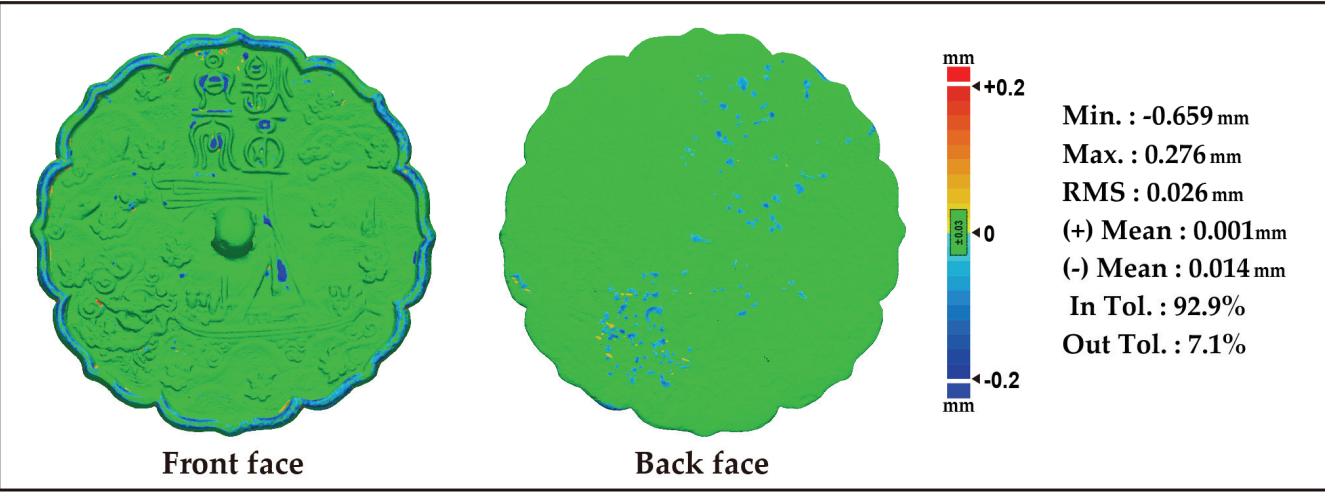

Figure 5. 3D deviation analysis before and after the virtual conservation treatment. 
4c). Furthermore, as a result of the shape analysis before and after the conservation treatment, the deviation was mainly within $0.1 \mathrm{~mm}$, and the surface area where the contaminants were removed was about $7.1 \%$ (Figure 5). The 3D model, which completed after the virtual conservation treatment based on the historical evidence, is valuable as the original data at the time of its creation, and it is likely to extend its uses to areas such as education, replication, and cultural products.

\subsection{Digital-mold modeling}

At present, there is no casting method for the bronze mirror with the Hwangbichangcheon inscription. Consequently, it is difficult to reproduce its original manufacturing technique. Therefore, mold-form modeling is required to increase the utilization of $3 \mathrm{D}$ data and the scalability of replication for metal casting. In this study, the mold of the mirror with coarse lines, which was excavated at Maengsan, Pyongannam-do and almost the only remaining one in Korea, was chosen as the reference model. This mold is presumed to have been created between the 7th and 5th century B.C., and it is known as a representative artifact of the Bronze Age in Korea.

First, to model the appearance of the mold of the mirror with coarse lines, the actual measurements of the size, thickness, and range of patterns based on its photograph were taken. The diameter of the mirror with coarse lines shown in the mold was estimated to be $202 \mathrm{~mm}$, which is about $30 \mathrm{~mm}$ larger than the diameter of the bronze mirror with the Hwangbichangcheon inscription (about $170 \mathrm{~mm}$ ). Thus, after reducing the mold of the mirror with coarse lines to about $84 \%$, the missing part was restored with the trend line to complete the model of the mold's appearance.

Boolean computational modeling was then performed to display the shape of the bronze mirror in the digital mold. In $3 \mathrm{D}$ graphics, the Boolean computation refers to the process of combining two objects, subtracting another from one object, or extracting a common part of two objects. Hence, it is an effective method of creating new complicated models by combining different forms of other models (Jo et al., 2020a; 2020b).

In this study, the patterns of the bronze mirror were modeled by subtracting the 3D model of the bronze mirror based on the model of mold's appearance built on the drawing with the actual measurements. Then, it was supplemented by the sprue and loop to complete the concave mold, and finally, the convex mold, which serves as a cover for metal casting, was modeled. In addition, a bronze mirror was digitally created to check the completeness of the digital mold, and the sharpness and replicability of the patterns were simulated (Figure 6). This enabled the defects in the shape
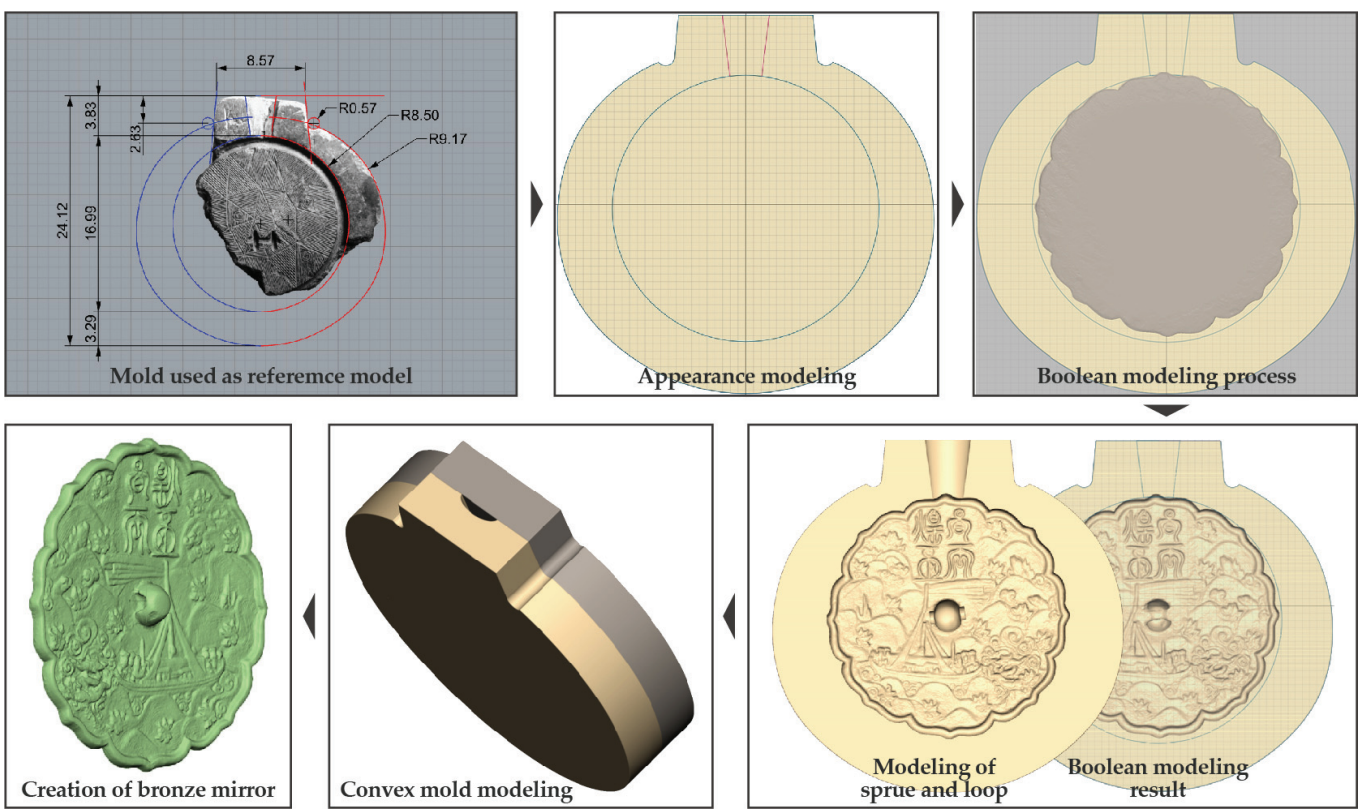

Figure 6. Digital-mold modeling process. 
to be identified in advance, which greatly reduced defects in the replica and enhanced the quality.

\subsection{D sand-printing}

$3 \mathrm{D}$ printing is a technology that differentiates $3 \mathrm{D}$ models developed through computer graphics, scans them into 2D sections, and reconstructs them continuously, based on the materials being built, layer by layer to make the shape. This technology varies widely in principles and according to materials printed (Balletti et al., 2017; Segreto et al., 2017; Turner et al., 2017; Xu et al., 2017; Vranich, 2018; Ford and Minshall, 2019); hence, it is important to select a 3D printing method suitable for the intended purpose. Basically, to replicate bronze mirrors, casting using alloyed metals is possible. The $3 \mathrm{D}$ printing method suited for realizing this is binder jetting using sand, which is commonly called sand-printing. Currently, this method is widely used as a key technology for sand casting in industries (Deng et al., 2018; Sama et al., 2018; 2019).

The materials used for the 3D printing of the digital mold include quartz (99\% purity and $140 \mu \mathrm{m}$ in size) and lowtemperature-cured furan resin. The layer thickness for the printing was set to $0.28 \mathrm{~mm}$ and the digital mold was printed out after inputting the model into the dedicated software. The sand was then removed using an air gun and the binder used in the layer was sufficiently dried at room temperature. The printout was further cured to increase its strength (Figure 7). This sand-printed mold is valuable in terms of the printout itself, but it is more useful in that it can be utilized in the actual casting.

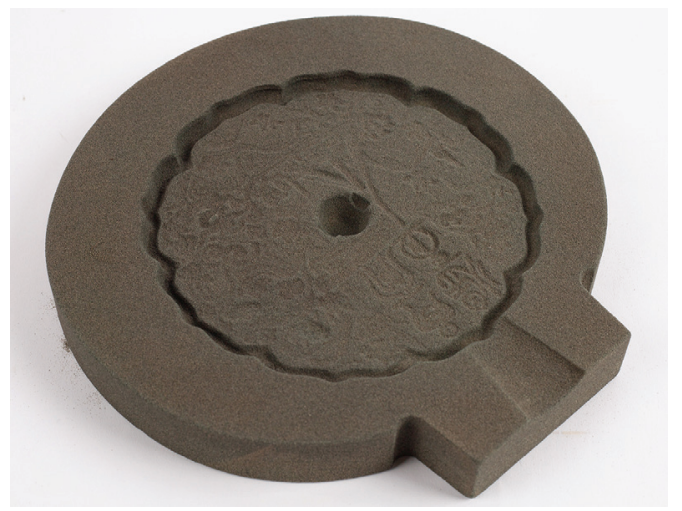

Figure 7. 3D sand-printing of the digital mold.

\section{DISCUSSION}

Replication of artifacts is a method of preserving and conserving the original form of artifacts, and it is performed for the purpose of exhibition, education, research, etc. An important principle and the ideal method of such replication is to reflect the philosophy, materials, methods, etc. as well as the form of the original artifact. However, as there is insufficient data available over the flow of historical time and the skills at the time of the creation of such artifacts are extinct, replication centered on imitating shapes is becoming commonplace. In addition, it is often impossible to reflect raw materials, and the rapid advancement in technology has led to a wide variety of replication methods (Balletti and Ballarin, 2019; Dong et al., 2020).

Despite these emergences of technologies and methodologies, the most important aim of replication is to ensure the stability of the original artifact. Moreover, precision, expressivity, collectivity, durability, and economic feasibility should be considered (Byun et al., 2009). In this study, 3D scanning and printing-based contactless replication were employed as a method to achieve the aforementioned conditions. In particular, a methodology is proposed to model and print the mold that reflects the creation process of the bronze mirror with Hwangbichangcheon inscription rather than replicating it directly.

Firstly, a high-resolution scanning model with a distance of $0.02 \mathrm{~mm}$ between points was completed, and for the virtual conservation treatment, the corrosion particles on the surface of the bronze mirror were removed using a haptic device after being converted to a voxel model. The outcome was the original bronze mirror, which is not only valuable as a heritage but also applicable in education, exhibition, and research. Most cultural products in museums are also made based on digital data; therefore, it can be utilized as a souvenir to highlight its function as a mirror (Figure 8).

For the virtually treated bronze mirror with Hwangbichangcheon inscription, the mold was created based on the reference model and Boolean modeling, thereby completing the digital mold with the pattern displayed. A virtual bronze mirror was created based on the digital mold and the sharpness and replicability of the pattern were checked in advance. This can greatly reduce defects in the final replica and enhance its quality. In addition, basically, 


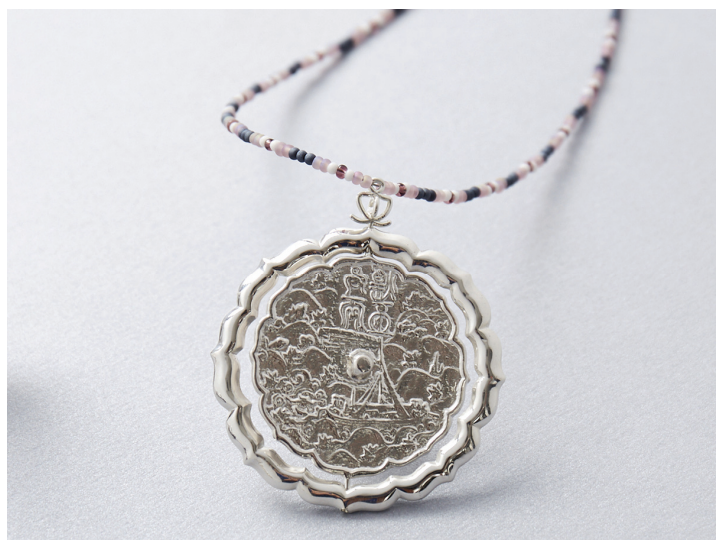

Figure 8. Cultural product of the bronze mirror with Hwangbichangcheon inscription.

molds printed with a 3D sand-printer are characterized by large pores among sand particles. This ensures good ventilation when casting a bronze mirror, which is advantageous in emitting water vapor or gases.

Reproducing a mold by 3D scanning, voxel modeling, virtual conservation treatment, Boolean modeling, and sand-printing is a method of replication that reflects the materials and technologies that change with time (Figure 9). Given that digitalization of artifacts has become common nowadays and $3 \mathrm{D}$ printing is widely used for restoration and replication (Lee and Wi, 2015; Jo and Hong, 2019; Shin and $\mathrm{Wi}, 2020)$, there is a need to develop new methodologies using advanced technologies. In particular, sand-printing based on digital-mold modeling is expected to be in high demand for metal artifacts that need casting or require continuous production due to their high utilization, like the ritual vessel used for ancestral rites at Jongmyo.

This study focused on establishing a creation process for a mold used in casting artifacts using digital technologies. This shortens the entire process by excluding the stage of casting the original artifact from the processes of creating the traditional metal artifacts. However, the replica was not created directly using the sand-printing mold in this study, hence, there is still a need for further research on the casting operation. It is inferred that the application of digital technology-based contactless replication methodology can be extended only if the on-site applicability is verified.

\section{CONCLUSION}

In this study, a contactless replication methodology that makes active use of digital technologies, including 3D scanning, voxel modeling, virtual conservation treatment, Boolean modeling, and 3D sand-printing, is proposed to replicate a bronze mirror with Hwangbichangcheon inscription. The mold for a bronze mirror could be created quickly by linking the outcome of a modeled mold to the sand-printing based on the original data of the mirror. This methodology minimizes contacts with artifacts and greatly contributes to streamlining conventional processes for replication.

The digital model of the bronze mirror created by $3 \mathrm{D}$ scanning displayed a high-resolution distance of $0.02 \mathrm{~mm}$ on average between points, and the overall inscription, pattern, texture, and corrosion on the surface were properly replicated. Since the corrosion on the surface should not be replicated, the polygon mesh was converted into a voxel model to

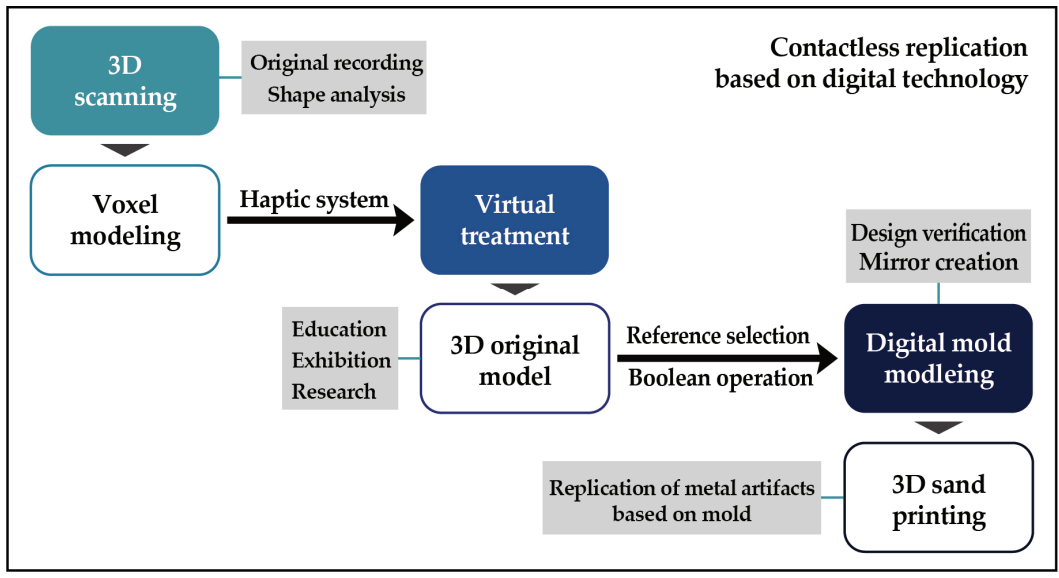

Figure 9. Suggestion of the digital technology-based contactless replication methodology for the bronze mirror. 
remove it, and virtual conservation treatment was performed using a digital haptic device. This eliminated $233 \mathrm{~mm}^{3}$ of the corrosion existing in about $7.3 \%$ of the surface area.

To model the digital mold for the bronze mirror, its drawing was produced with the actual measurements based on reference data, and its overall appearance was completed by adjusting its size. The pattern plane was displayed by differentiating the virtually treated $3 \mathrm{D}$ model of the bronze mirror with the Boolean computation. Then, the sprue shape was added based on the drawing and the loop was completed crossing a thin digital clay bar to make a hole after casting. The convex mold was created for the metal casting. The completed model of the mold was printed out by binder-jetting-based 3D sand-printing.

This digital technology-based contactless replication reflects the stability, precision, expressivity, collectivity, durability, and economic feasibility of artifacts, and its application can be extended to cultural products as well as such areas as education, exhibition, and research in the future. It could also be in high demand for metal artifacts that require continuous production of replicas because they require casting or have high demand. However, in this study, the replica was not created directly using the sand-printing mold; hence, further research on the casting operation is needed. This shows that the application of the digital technology-based contactless replication methodology can be extended only if the on-site applicability is verified.

\section{ACKNOWLEDGMENTS}

This work was supported by the National Research Foundation of Korea (NRF) grant funded by the Korean government (MSIT) (NRF 2019R1F1A1060671).

\section{REFERENCES}

Abidi, M.H. and Ahmad, A., 2015, Haptics assisted virtual assembly. IFAC-PapersOn-Line, 48, 100-105.

Ahn, H.K., 2017, Utilizing archaeological dataset through the application of 3D printer. The Journal of Korean Field Archaeology, 30, 249-282. (in Korean with English abstract)

Balletti, C. and Ballarin, M., 2019, An application of integrated 3D technologies for replicas in cultural heritage. International Journal of Geo-Information, 8, 285.
Balletti, C., Ballarin, M. and Guerra, F., 2017, 3D printing: state of the art and future perspectives. Journal of Cultural Heritage, 26, 172-182.

Byun, S.M., Park, G.J. and Lim, S.H., 2009, A study on replication of relics by contact and non-contact methods. The Journal of Conservation of Cultural Properties, 6, 53-73. (in Korean with English abstract)

Corrêa, C.G., Nunes, F.L.S., Ranzini, E., Nakamura, R. and Tori, R., 2019, Haptic interaction for needle insertion training in medical applications: the state-of-the-art. Medical Engineering \& Physics, 63, 6-25.

Deng, C., Kang, J., Shangguan, H., Hu, Y., Huang, T. and Liu, Z., 2018, Effects of hollow structures in sand mold manufactured using 3D printing technology. Journal of Materials Processing Technology, 255, 516-523. (in Korean with English abstract)

Di Franco, P.D.G., Camporesi, C., Galeazzi, F., and Kallmann, M., 2015, 3D printing and immersive visualization for improved perception of ancient artifacts. Presence, 24, 243-264.

Dong, Q., Zhang, Q. and Zhu, L., 2020, 3D scanning, modeling, and printing of Chinese classical garden rockeries: Zhanyuan's South Rockery. Heritage Science, 8,61 .

Ford, S. and Minshall, T., 2019, Invited review article: where and how 3D printing is used in teaching and education. Additive Manufacturing, 25, 131-150.

Jo, Y.H. and Hong, S., 2019, Application of three-dimensional scanning, haptic modeling, and printing technologies for restoring damaged artifacts. Journal of Conservation Science, 35, 71-80. (in Korean with English abstract)

Jo, Y.H., Hong, S., Jo, S.Y. and Kwon, Y.M., 2020a, Noncontact restoration of missing parts of stone Buddha statue based on three-dimensional virtual modeling and assembly simulation. Heritage Science, 8, 103.

Jo, Y.H., Yeo, J.M. and Kim, Y.T., 2020b, Applying digital virtual restoration and three-dimensional sand-printing for missing parts of ramparts walls. TEST Engineering \& Management, 83, 4387-4394.

Jung, S.H., 2015, The iconography and significance of motifs on Goryeo bronze mirrors with the inscription of Hwangbichangcheon. Korean Journal of Art History, 286, 59-85. (in Korean with English abstract)

Kuş, A., 2009, Implementation of 3D optical scanning technology for automotive applications. Sensors, 9, 1967-1979.

Kwon, D.K. and Jo, Y.H., 2019, Visualization and analysis of surface shape for bronze mirror using threedimensional rendering technologies. Science and 
Engineering of Cultural Heritage, 14, 71-76. (in Korean with English abstract)

Lee, H.S. and Wi, K.C., 2015, Restoration of earthenware \& porcelain cultural assets using 3D printing. Journal of Conservation Science, 31, 131-145. (in Korean with English abstract)

Lee, H.S., 2018, Restoration of cultural properties using replication techniques. The Journal of the Korea Society of Art \& Design, 21, 64-85. (in Korean with English abstract)

Lim, H.W. and Choi, W.H., 2020, Restoration of Joseon's mortar used during the Japanese invasion of Korea in 1592. The Journal of the Korea Contents Association, 20, 56-65. (in Korean with English abstract)

Merchán, M.J., Merchán, P., Salamanca, S., Pérez, E. and Nogales, T., 2019, Digital fabrication of cultural heritage artwork replicas. In the search for resilience and socio-cultural commitment. Digital Application in Archaeology and Cultural Heritage, 15, e00125.

Oh, S. and Wi, K.C., 2018, A study on the method of restoring pottery using $3 \mathrm{D}$ digital technology: comparison of the restoring methods of white porcelain using contact and contactless methods. Culture and Convergence, 40, 595-614. (in Korean with English abstract)

Rastogi, N. and Srivastava, A.K., 2019, Control system design for tokamak remote maintenance operations using assisted virtual reality and haptic feedback. Fusion Engineering and Design, 139, 47-54.

Sama, S.R., Badamo, T., Lynch, P. and Manogharan, G., 2019, Novel sprue designs in metal casting via 3D sand-printing. Additive Manufacturing, 25, 563-578.

Sama, S.R., Wang, J. and Manogharan, G., 2018, Non-conventional mold design for metal casting using 3D sand-printing. Journal of Manufacturing Process, 34, 765-775.

Segreto, T., Bottillo, A., Teti, R., Galantucci, L.M.,
Lavecchia, F. and Galantucci, M.B., 2017, Non-contact reverse engineering modeling for additive manufacturing of down scaled cultural artefacts. Procedia CIRP, 62, 481-486.

Seol, J.E., 2015, A study on the bronze mirrors excavated in the tombs of Goryeo in the Hoseo region. Master's dissertation, Dongguk University, Seoul. (in Korean with English abstract)

Shin, W.C. and Wi, K.C., 2020, A study on ceramic restoration methods with full color $3 \mathrm{D}$ printing. Journal of Conservation Science, 36, 306-314. (in Korean with English abstract)

Turner, H., Resch, G., Southwick, D., McEwen, R., Dube, A.K. and Record, I., 2017, Using 3D printing to enhance understanding and engagement with young audiences: lessons from workshops in a museum. Curator The Museum Journal, 60(3), 311-333.

Vranich, A., 2018, Reconstructing ancient architecture at Tiwanaku, Bolivia: the potential and promise of $3 \mathrm{D}$ printing. Heritage Science, 6, 65.

Wu, W., Cen, Y., Hong, Y., Keeling, A. and Khambay, B., 2016, A pilot study to assess the feasibility and accuracy of using haptic technology to occlude digital dental models. Journal of Dentistry, 46, 54-60.

Xu, J., Ding, L. and Love, P.E.D., 2017, Digital reproduction of historical building ornamental components: from 3D scanning to $3 \mathrm{D}$ printing. Automation in Construction, 76, 85-96.

Yun, Y.H. and Cho, N.C., 2012, The restoration technology and scientific analysis of bronze mirror with fine linear designs. Journal of Conservation Science, 28 (4), 417-425. (in Korean with English abstract)

Yun, Y.H., Yun, S.B. and Jeong, Y.S., 2015, Restoration and manufacturing techniques of bronze mirror stone cast. Journal of Museum Studies, 29, 121-149. (in Korean with English abstract) 